\title{
InSb/InAISb гетероструктуры для ИК фотоприемников с повышенной рабочей температурой
}

\author{
М.А. Суханов, А.К. Бакаров, И.Д. Лошкарев, К.С. Журавлев \\ Институт физики полупроводников им. А.В. Ржанова, Новосибирск,
} 630090, пр. Академика Лаврентьева, 13

DOI $10.34077 /$ RCSP2021-84

Антимонид индия - полупроводник, применяемый для создания фотоприемников ИК диапазона от 1 до 5 мкм, работающих при криогенных температурах. Основным ограничением InSb фотоприемников является темновой ток, подавление которого достигается понижением рабочей температуры устройства до $77 \mathrm{~K}$, что увеличивает вес, стоимость и размер устройства. Основной альтернативой традиционным pin InSb фотодиодам являются $\mathrm{nBn}$ - гетероструктуры InSb/InAlSb, состоящие из контактного (n), барьерного (B) и поглощающего слоев(n) [1]. Данная гетероструктура обладает меньшей степенью обеднения и шириной ОПЗ, встроенный барьер позволяет подавить темновой ток электронов со стороны контактного слоя и поверхностный ток утечки, что, по сравнению c pin фотодиодами, позволяет повысить рабочую температуру фотоприемника без повышения плотности темнового тока, или наоборот, повысить чувствительность при неизменной температуре. При приложении отрицательного смещения к контактному слою, фотогенерированные в поглощающем слое дырки перемещаются к контактному слою под действием поля. В данной работе были измерены темновые и фототоки, проведено изучение роста методом молекулярно-лучевой эпитаксии $\mathrm{nBn}$-гетероструктур $\mathrm{InSb} / \mathrm{In}_{1-\mathrm{x}} \mathrm{Al} \mathrm{l}_{\mathrm{x}} \mathrm{Sb}$ на подложках $\mathrm{InSb}(001)$, где $\mathrm{In}_{1-\mathrm{x}} \mathrm{Al} \mathrm{x}_{\mathrm{x}} \mathrm{Sb}$ является широкозонным барьером (B). Ввиду наличия рассогласования между постоянными решетки барьерного слоя и подложки InSb, необходимо определить оптимальную долю алюминия и толщину барьера, при которой слой InAlSb будет псевдоморфным, для этого была выращена серия слоев InAlSb с постоянной $\mathrm{x}=0.4,0.3,0.2$ и переменной долей алюминия, в варизонных барьерах доля алюминия изменялась от 0.4 до 0.1 (I) и от 0.35 до 0.15 (II) в процессе роста структуры от поглощающего слоя к контактному. Контроль состояния поверхности в процессе роста проводился методом дифракции

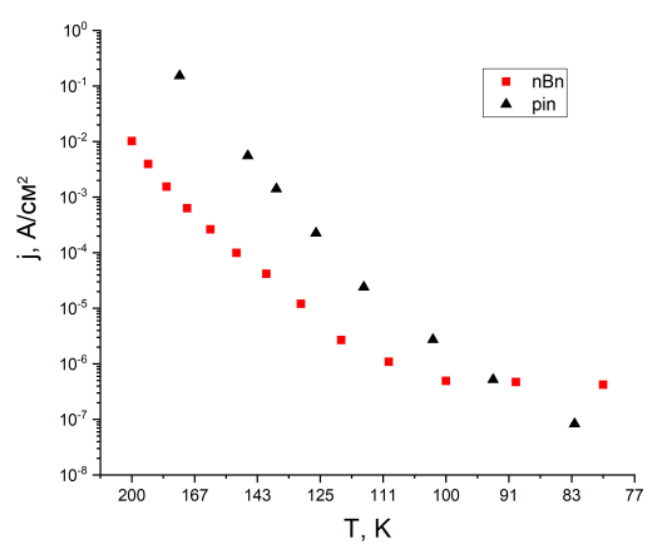

Рис. 1. Сравнение темнового тока InSb pin и $\mathrm{InSb} / \mathrm{InAlSb} \mathrm{nBn}$ структур при $\mathrm{U}=-50 \mathrm{MB}$. быстрых электронов. После роста был проведен анализ выращенных слоев методом рентгеновской дифракции с определением степени релаксации слоя InAlSb. Согласно рентгеновской дифракции, степень релаксации варизонного барьера типа II близка к 0. Для образца со варизонным барьером I наблюдается релаксация слоя InAlSb. На основе выращенных гетероструктур изготовлены мезаструктуры с площадью металлизации от 50 до 200 мкм методами жидкостного травления и фотолитографии, измерена температурная зависимость темнового тока, а также фототок. Смоделированы зонные диаграммы, а также диффузионный, генерационнный и туннельный темновые токи выращенных $\mathrm{nBn}$. Теоретически рассчитанный темновой ток меньше, чем экспериментальный, поэтому, по-видимому, преобладающим является ток туннелирования электронов со из контактного слоя в поглощающий через ловушки в барьере. Продемонстрировано, что при смещении -50 мВ и диапазоне температур от 100 до $200 \mathrm{~K}$, темновой ток nBn InSb/InAlSb с варизонным барьером II меньше, чем у традиционных pin фотодиодов в $10-100$ раз для 100 К и 200 К соответственно (рисунок 1), что указывает на возможность использования InSb/InAlSb гетероструктур для изготовления ИК фотоприемников с повышенной рабочей температурой.

\section{Лumepamypa}

[1] Savich G. R. et al. Benefits and limitations of unipolar barriers in infrared photodetectors. Infrared Physics \& Technology. 2013. T. 59. C. 152-155. 